\title{
Extract from the stem of Tinospora crispa (L.) Hook. f. \& Thomson extends life span and decreases stress-induced mortality in Drosophila melanogaster
}

\author{
Nattapong Wongchum ${ }^{1}$, Ananya Dechakhamphu'2,3* \\ 1 Biology Program, Faculty of Science, Ubon Ratchathani Rajabhat University, Ubonratchathani, Thailand \\ Thai Traditional Medicine Program, Faculty of Thai Traditional and Alternative Medicine, Ubon Ratchathani Rajabhat University, Ubonratchathani, \\ Thailand \\ Aesthetic Sciences and Health Program, Faculty of Thai Traditional and Alternative Medicine, Ubon Ratchathani Rajabhat University, Ubonratchathani, \\ Thailand
}

\begin{abstract}
Aging plays a significant role in the development of degenerative diseases. The stem of Tinospora crispa has been recorded to use as longevity medicine in ancient Thai manuscripts. However, there is no experimental data to verify this property. This study aimed to verify the anti-aging activity of $T$. crispa extract (TCE) in Drosophila melanogaster. The effects of TCE on the life span and the resistance to stressors, including free radicals, heat and cold shocks, and starvation, were investigated in D. melanogaster. When compared to the control diet, TCE supplementation at $20 \mathrm{mg} / \mathrm{mL}$ in mixed diets increased in the $50 \%$ survival time by $18.37 \%$. On days 25 and 40, TCE-treated flies showed a significant increase in climbing ability when compared to control flies. In TCE-treated flies, significant increases in superoxide dismutase (SOD1 and SOD2) and catalase (CAT) activities were found at days 25 and 40. The findings of the paraquat and $\mathrm{H}_{2} \mathrm{O}_{2}$ challenge tests revealed that flies given TCE at $20 \mathrm{mg} / \mathrm{mL}$ survived longer than control flies. TCE supplementation increased resistance to starvation and acetic acid-induced stress, as well as recovery from cold and heat shocks. This study provides experimental data on the significance of dietary TCE supplementation in extending life span and reducing stressinduced mortality in Drosophila.
\end{abstract}

\section{Keywords:}

Healthy aging, Plant extract, Anti-aging, Longevity, Stress tolerance

\section{INTRODUCTION}

Aging is well recognized as a substantial risk factor for chronic diseases such as cancer, heart disease, diabetes, and various degenerative disorders ${ }^{1}$. Currently, elderly patients are strongly associated with a risk of mortality from COVID-19 infection ${ }^{2}$. The older population is now rapidly increasing around the world. It has been postulated that one in six people in the world will be over 65 years by $2050^{3}$. In the coming decades, many countries are likely to face an aging population. As a result, supplying and maintaining a healthy life expectancy for the elderly is a fundamental challenge for the global human services system. The Free Radical Theory of Aging is considered the most acceptable postulates to explain the aging process at the cellular level, despite the fact that over 300 theories of aging have been proposed ${ }^{4}$ 5 . The over-production of endogenous reactive oxygen species (ROS) can cause oxidative damage to macromolecules such as DNA, proteins, and lipids, signifycantly influencing the life $\operatorname{span}^{6-7}$. Endogenous enzymes like superoxide dismutase (SOD), catalase (CAT), and glutathione peroxidase (GPx), as well as exogenous antioxidants like vitamin $\mathrm{E}$ and carotenoids, are used by organisms to scavenge free radicals ${ }^{8}$. As a consequence, improving antioxidant systems and lowering ROS levels should help expand life expectancy. Drosophila melanogaster, or fruit fly, is a powerful model for aging research

*Corresponding author:

*Ananya Dechakhamphu ananya.d@ubru.ac.th 
relevant to humans. This model organism shares more than $70 \%$ of disease-causing genes with humans ${ }^{9-11}$. The number of publications studying the longevity effect of phytochemical compounds in Drosophila has increased ${ }^{12}$. Consequently, Drosophila has been shown to be a reliable model organism for dietary-induced life span extension ${ }^{13}$. Additionally, in longevity research, the fruit fly has been shown to be a quick and cost-effective model system because of its short life spans, low chromosomal number, high fertility, ease of handling, and flexibility to manipulate genetic background and experimental settings.

Several phytochemical substances and extracts have been shown to extend the life span of lower model organisms $^{14-15}$. Throughout traditional Thai medicine history, medicinal plants have been used as longevity treatment for over 300 years, including Tinospora crispa (L.) Hook. f. \& Thomson (Menispermaceae). This plant is widely distributed in Thailand, Malaysia, and Indone$\mathrm{sia}^{16}$. The stem of this plant has been used as a longevity medicine in ancient Thai manuscripts, either as a single treatment or as an ingredient in a recipe. Also, it has been used in traditional Thai medicine as an antipyretic, blood and body nourishing tonics, decreasing thirst, and appetite stimulation. The pharmacological properties of T. crispa were associated with the anti-inflammatory ${ }^{17-}$ ${ }^{18}$, antioxidant ${ }^{19-20}$, antinociceptive ${ }^{21}$, cytotoxicity ${ }^{22-23}$, antimalarial $^{24}$, hypoglycaemic ${ }^{25-26}$, cardiovascular ${ }^{27-28}$, and immunomodulatory activities ${ }^{29}$. Based on the previous research data, it can be clued that $T$. crispa extract may act as an anti-aging agent. However, no data on the property of longevity has been reported. Therefore, the longevity effect of $T$. crispa extract (TCE) in the fruit fly is investigated in this study. To explain the mechanism of action, the antioxidant effect and antioxidant enzyme activities were evaluated. TCE's effects on the improvement of cold and heat shock recovery and starvation stress resistance in TCE-treated flies were also studied.

\section{MATERIALS AND METHODS}

\subsection{Plant material and preparation of extract}

The stems of T. crispa were collected from a local cultivation for traditional medicine and other common uses in Ubonratchathani Province, Thailand, voucher specimen TC001. Plant materials were dried and processed into a fine powder in a hot air oven at $55^{\circ} \mathrm{C}$ for 72 hours. The maceration method was used to soak 50 grams of powder in $250 \mathrm{~mL}$ absolute ethanol for 7 days at room temperature $\left(25-30^{\circ} \mathrm{C}\right)$. The extracts were filtered through Whatman No. 40 filter paper and concentrated using a rotary evaporator (Buchi R-210, Flawil, Switzerland). The extracts were refrigerated at $-20^{\circ} \mathrm{C}$ until used.

\subsection{Culturing of Drosophila}

The wild type D. melanogaster Oregon-R-C strain was obtained from the Department of Biology, Khon Kaen University. The flies were housed in a lab atmosphere at a temperature of $25 \pm 1.2^{\circ} \mathrm{C}$ with a relative humidity of $70-80 \%$ on a $12: 12$ light/dark cycle. The control diet was traditional wheat cream agar media seeded with yeast granules (10\% wheat flour w/v, $10 \%$ sucrose $\mathrm{w} / \mathrm{v}, 2 \%$ agar $\mathrm{w} / \mathrm{v}, 3 \%$ yeast granules $\mathrm{w} / \mathrm{v}$, and $0.75 \%$ propionic acid $\mathrm{v} / \mathrm{v}$ ). The diet was prepared by boiling $1,000 \mathrm{~mL}$ of water with $20 \mathrm{~g}$ of agar and $100 \mathrm{~g}$ of sucrose. After the agar and sucrose were completely melted, $100 \mathrm{~g}$ wheat flour and $7.5 \mathrm{~mL}$ propionic acid were added. Finally, $30 \mathrm{~g}$ yeast granules were added gradually. $5 \mathrm{~mL}$ of diet was divided into $8 \mathrm{~cm} \times 2.5 \mathrm{~cm}$ glass vials and covered with sterilized cotton. To prepare TCE-containing diets, TCE was added at final concentrations of 10 and $20 \mathrm{mg} / \mathrm{mL}$ directly to a control diet at $45-50^{\circ} \mathrm{C}$ to prevent extract degradation. Following the addition of TCE, mix immediately before the diet becomes jelly and maintain the diet at $25^{\circ} \mathrm{C}$ for $18 \mathrm{~h}$ to allow the steam to completely evaporate.

Every two days, the survivors were transferred to new food vials. The animal research design was approved by the Ethic Committee of Ubon Ratchathani Rajabhat University, Thailand (Ethical Clearance No. AN63001).

\subsection{The gustatory assay}

The gustatory assay was used to measure food intake, with minor modifications from Balasubramani et al. $(2014)^{30}$. Newly eclosed male flies were fed a control diet for seven days, then they were starved for $2 \mathrm{~h}$. Flies were allocated randomly to extract-supplemented diets containing bromophenol blue dye $(0.05 \% \mathrm{wt} / \mathrm{vol})$ (SigmaAldrich, St. Louis, MO, USA) or control diets for $2 \mathrm{~h}$. The fed flies were then etherized with $5 \% \mathrm{CO}_{2}$, rinsed in $0.1 \mathrm{mM}$ phosphate-buffered saline, and homogenized in $1 \mathrm{~mL}$ distilled water. The supernatant was analyzed at $595 \mathrm{~nm}$ with a spectrophotometer (Biochrome, UK) to evaluate food intake. The data were presented as a mean and standard deviation.

\subsection{Longevity assay}

Following the results of the gustatory assay, the longevity assay was performed using TCE at concentrations of 10 (TCE10) and 20 (TCE20) $\mathrm{mg} / \mathrm{mL}$ in a supplemented diet. The protocol for the study was followed as it was described ${ }^{31}$. Newly eclosed male files were divided into three groups ( $\mathrm{n}=200$ each, 20 per vial), including control, TCE10, and TCE20 groups. The TCE10 and TCE20 groups were fed with diets containing 10 and $20 \mathrm{mg} / \mathrm{mL}$ TCE, respectively, whereas the control 
group was fed with a control diet. Every two days, the flies were transferred to a new feeding vial containing the same diet. The number of dead flies was recorded every 2 days. The data were expressed as the survival curves. The second experiment was duplicated, the flies were sacrificed on days 25 and 40 to measure SOD and CAT activities as well as quantify malondialdehyde (MDA) levels.

\subsection{In vivo antioxidant assay}

\subsubsection{Intensive paraquat challenge test}

Superoxide anion radicals were generated by using paraquat $\left(1,1^{\prime}\right.$-dimethyl-4,4'-bi-pyridinium dichloride, Sigma, St. Louis, MO, USA). Newly eclosed male flies were reared on the control diet or diet containing TCE10 and TCE20 ( $\mathrm{n}=200$ each, 20 per vial) to evaluate the resistance to superoxide-induced oxidative stress. On day 25 (adult flies) and 40 (aged flies), the flies in each group were fasted for $2 \mathrm{~h}$ in an empty vial containing distilled water-soaked filter paper before being transferred to separate vials containing filter paper saturated with $20 \mathrm{mM}$ paraquat in a $6 \%$ sucrose solution. The number of deceased flies was counted every $4 \mathrm{~h}$ until the death of the last fly.

\subsection{2. $\mathrm{H}_{2} \mathrm{O}_{2}$ challenge test}

Hydroxyl radical $\left({ }^{\circ} \mathrm{OH}\right)$ was generated by using $\mathrm{H}_{2} \mathrm{O}_{2}$ (Sigma, St. Louis, MO, USA). A control diet or a diet with TCE10 and TCE20 $(n=200$ each, 20 per vial) were fed to newly eclosed male flies for 25 and 40 days. The flies in each group were starved for $2 \mathrm{~h}$ in an empty vial containing filter paper soaked in distilled water, then transferred to separate vials containing a filter paper saturated with $30 \% \mathrm{H}_{2} \mathrm{O}_{2}$ in a $6 \%$ sucrose solution for evaluating resistance to hydroxyl radicalinduced oxidative stress. The number of deceased flies was counted every $4 \mathrm{~h}$ until the death of the last fly.

\subsubsection{SOD activity}

The indirect technique was utilized to test SOD activity by using a kit provided by Sigma-Aldrich (USA) and following the supplier's procedure, adding samples' preparation. Twenty flies per vial were homogenized in $1 \mathrm{~mL}$ of cold buffer solution (kit provided) ( $n=200$ per group). The debris of the fly was removed by centrifugation at $1,500 \mathrm{rpm}$ at $4^{\circ} \mathrm{C}$ for $5 \mathrm{~min}$. The supernatant $(900 \mathrm{uL})$ was then pipetted into a $1.5 \mathrm{~mL}$ microcentrifuge tube and centrifuged at $10,000 \mathrm{~g}$ for 15 min at $4^{\circ} \mathrm{C}$. The activity of SOD1 (CuZn SOD) was measured in the supernatant, wherease, SOD2 (Mn SOD) activity was measured using the pellet redissolved in $0.5 \mathrm{~mL}$ cold buffer. All of the samples were tested in triplicate.

\subsubsection{CAT activity}

The CAT activity in the sample was determined using a Sigma-Aldrich (USA) kit following the supplier's protocol. Twenty flies were homogenized in $1 \mathrm{~mL}$ of cold enzyme dilution buffer ( $\mathrm{n}=200$ per group). Fly's debris was removed by centrifugation at $1,500 \mathrm{~g}$ at $4^{\circ} \mathrm{C}$ for $5 \mathrm{~min}$. The supernatant $(500 \mathrm{uL})$ was then diluted in $10 \mathrm{~mL}$ of assay buffer $(5 \mathrm{mM}$ potassium phosphate buffer, $\mathrm{pH}$ 7.0). As of diluted sample, $75 \mu \mathrm{L}$ were mixed with $25 \mu \mathrm{L}$ of $200 \mathrm{mM}$ hydrogen peroxide solution and incubated for $1 \mathrm{~min}$. After that, $900 \mu \mathrm{L}$ of stop solution (15 mM sodium azide) were added to stop the reaction. The reaction mixture $(10 \mu \mathrm{L})$ was then mixed with $1 \mathrm{~mL}$ of color reagent ( $2 \mathrm{mM}$ 3,5-dichloro-2-hydroxybenzenesulfinic acid, $0.25 \mathrm{mM}$ 4-aminoantipyrine, and 0.5 $1.5 \mathrm{U} / \mathrm{mg}$ peroxidase). After $15 \mathrm{~min}$ of incubation at room temperature, the absorbance at $520 \mathrm{~nm}$ was measured using a spectrophotometer (Biochrome, UK). All of the samples were tested in triplicate.

\subsubsection{Measurement of lipid peroxidation}

The thiobarbituric acid reaction (TBAR) method utilized in this work was described by Devasagayam et al. $(2003)^{32}$. Adult flies aged 25 and 40 days from each experimental group were used to measure malondialdehyde (MDA) contents. In each tube, twenty flies were homogenated in $1 \mathrm{~mL}$ of cold PBS (50 mM, pH 7.0) ( $n=200$ per group). Of the homogenated solution, $500 \mu \mathrm{L}$ were mixed with $10 \mathrm{~mL}$ of TBA reagent $(0.37 \%$ TBA, $15 \% \mathrm{TCA}$ and $0.24 \mathrm{~N} \mathrm{HCl}$ ). After boiling for $15 \mathrm{~min}$, the mixture was cooled and centrifuged for 10 minutes at $3,000 \mathrm{rpm}$. The concentration of MDA in the samples was measured spectrophotometrically (Biochrome, England) at $532 \mathrm{~nm}$, and the standard 1,1,3,3-tetramethoxy propane plot was used to estimate the concentration of MDA in the samples.

\subsection{Climbing assay}

The physical strength of flies in the three groups was assessed using a climbing assay. The method was adjusted from that which previously been reported by Lee et al. (2009) ${ }^{33}$. In each climbing trial, 20 male flies were collected on days 25 and 40 and incubated for 30 minutes at $25^{\circ} \mathrm{C}$ for adaptation ( $\mathrm{n}=200$ per group). The flies were then gently tapped to the bottom of the test $\operatorname{vial}(2.5 \times 200 \mathrm{~mm})$ and given $20 \mathrm{~s}$ to crawl back up. The number of flies that climbed $15 \mathrm{~cm}$ or more vertically was counted. Every test was carried out three times.

\subsection{Cold shock recovery}


The recovery from cold shock was evaluated as previously described by Colpo et al. (2017) ${ }^{34}$. Flies were maintained in diets with or without TCE (10 and $20 \mathrm{mg} / \mathrm{mL}$ ) for 25 and 40 days ( $\mathrm{n}=200$ per group). On days 25 and 40, flies were placed in empty vials and allowed to adapt for $30 \mathrm{~min}$ at $25^{\circ} \mathrm{C}$. After adaptation, flies were maintained at $-5^{\circ} \mathrm{C}$ in a cold bath comprised of ice and salt for 30 minutes. The flies were then transferred to a food vial and incubated at a temperature of $25 \pm 1.2^{\circ} \mathrm{C}$. The number of dead flies was recorded every day until the death of the last fly.

\subsection{Heat shock recovery}

The method was followed as previously described by Chattopadhyay et al. $(2017)^{35}$. Flies were maintained in diets with or without TCE (10 and 20 $\mathrm{mg} / \mathrm{mL}$ ) for 25 and 40 days ( $\mathrm{n}=200$ per group). On days 25 and 40, flies were placed in empty vials and allowed to adapt for $30 \mathrm{~min}$ at $25^{\circ} \mathrm{C}$. After adaptation, flies were incubated at $38^{\circ} \mathrm{C}$ for $60 \mathrm{~min}$ in hot-air incubation. The flies were then transferred to a food vial and incubated at a temperature of $25 \pm 1.2^{\circ} \mathrm{C}$. The number of dead flies was recorded every day until the death of the last fly.

\subsection{Acetic acid resistance}

The method was modified from previously described by Montooth et al. $(2017)^{36}$. Flies were maintained in diets with or without TCE (10 and 20 $\mathrm{mg} / \mathrm{mL}$ ) for 25 and 40 days ( $\mathrm{n}=200$ per group). On days 25 and 40, flies were placed in empty vials with filter paper soaked in distilled water and starved for $2 \mathrm{~h}$. After starvation, flies were placed into separate vials containing a filter paper saturated with $12 \%$ acetic acid (prepare with 6\% sucrose solution). Dead files were recorded every day until the death of the last fly.

\subsection{Starvation stress}

The method was modified from previously described by Colpo et al. $(2017)^{34}$. Flies were reared in diets with or without TCE (10 and $20 \mathrm{mg} / \mathrm{mL})$ for 25 and 40 days ( $\mathrm{n}=200$ per group). On days 25 and 40, flies were placed in vials containing only $2 \%$ agarose to provide moisture in the absence of food. Dead files were

Table 1. GC-MS analysis of the ethanolic extract from stems of T. crispa.

\begin{tabular}{|c|c|c|c|}
\hline No & Name & RT (min) & Formula \\
\hline 1 & $n$-Propyl acetate & 2.8287 & $\mathrm{C}_{5} \mathrm{H}_{10} \mathrm{O}_{2}$ \\
\hline 2 & Butane, 1,2:3,4-diepoxy-, (.+/-.)- & 2.9801 & $\mathrm{C}_{4} \mathrm{H}_{6} \mathrm{O}_{2}$ \\
\hline 3 & Hydrogen isocyanate & 3.0705 & CHNO \\
\hline 4 & Propanoic acid, 2-oxo-, methyl ester & 3.2147 & $\mathrm{C}_{4} \mathrm{H}_{6} \mathrm{O}_{3}$ \\
\hline 5 & Oxime-, methoxy-phenyl- & 4.4623 & $\mathrm{C}_{8} \mathrm{H}_{9} \mathrm{NO}_{2}$ \\
\hline 6 & 1,2-Cyclopentanedione & 4.9802 & $\mathrm{C}_{5} \mathrm{H}_{6} \mathrm{O}_{2}$ \\
\hline 7 & 2-Hydroxy-gamma-butyrolactone & 6.2590 & $\mathrm{C}_{4} \mathrm{H}_{6} \mathrm{O}_{3}$ \\
\hline 8 & $1,3,5,7$-Tetroxane & 6.6849 & $\mathrm{C}_{4} \mathrm{H}_{8} \mathrm{O}_{4}$ \\
\hline 9 & Undecane & 8.5312 & $\mathrm{C} 11 \mathrm{H} 24$ \\
\hline 10 & 4H-Pyran-4-one, 2,3-dihydro-3,5-dihydroxy-6-methyl- & 9.8892 & $\mathrm{C}_{6} \mathrm{H}_{8} \mathrm{O}_{4}$ \\
\hline 11 & (E)-4-(3-Hydroxyprop-1-en-1-yl)-2-methoxyphenol & 24.5660 & $\mathrm{C}_{10} \mathrm{H}_{12} \mathrm{O}_{3}$ \\
\hline 12 & Hexadecanoic acid, methyl ester & 28.1481 & $\mathrm{C}_{17} \mathrm{H}_{34} \mathrm{O}_{2}$ \\
\hline 13 & $n$-Hexadecanoic acid & 28.8603 & $\mathrm{C}_{16} \mathrm{H}_{32} \mathrm{O}_{2}$ \\
\hline 14 & Hexadecanoic acid, ethyl ester & 29.4672 & $\mathrm{C}_{18} \mathrm{H}_{36} \mathrm{O}_{2}$ \\
\hline 15 & trans-Sinapyl alcohol & 29.6763 & $\mathrm{C}_{11} \mathrm{H}_{14} \mathrm{O}_{4}$ \\
\hline 16 & 9-Octadecenoic acid, methyl ester, $(E)$ - & 31.4545 & $\mathrm{C}_{19} \mathrm{H}_{36} \mathrm{O}_{2}$ \\
\hline 17 & Phytol & 31.6789 & $\mathrm{C}_{20} \mathrm{H}_{40} \mathrm{O}$ \\
\hline 18 & Methyl stearate & 31.9189 & $\mathrm{C}_{19} \mathrm{H}_{38} \mathrm{O}_{2}$ \\
\hline 19 & cis-13-Octadecenoic acid & 32.1451 & $\mathrm{C}_{18} \mathrm{H}_{34} \mathrm{O}_{2}$ \\
\hline 20 & 9,12-Octadecadienoic acid, ethyl ester & 32.5526 & $\mathrm{C}_{20} \mathrm{H}_{36} \mathrm{O}_{2}$ \\
\hline 21 & Ethyl oleate & 32.6603 & $\mathrm{C}_{20} \mathrm{H}_{38} \mathrm{O}_{2}$ \\
\hline 22 & Glycerol 1-palmitate & 38.3027 & $\mathrm{C}_{19} \mathrm{H}_{38} \mathrm{O}_{4}$ \\
\hline 23 & $Z$-17-Nonadecen-1-ol acetate & 41.0303 & $\mathrm{C}_{21} \mathrm{H}_{40} \mathrm{O}_{2}$ \\
\hline 24 & 11-Hexadecen-1-ol, $(Z)$ - & 41.0315 & $\mathrm{C}_{16} \mathrm{H}_{32} \mathrm{O}$ \\
\hline 25 & Campesterol & 48.2137 & $\mathrm{C}_{28} \mathrm{H}_{48} \mathrm{O}$ \\
\hline 26 & Stigmasterol & 48.6300 & $\mathrm{C}_{29} \mathrm{H}_{48} \mathrm{O}$ \\
\hline 27 & 24-Norursa-3,12-diene & 49.0024 & $\mathrm{C}_{29} \mathrm{H}_{46}$ \\
\hline 28 & gamma-Sitosterol & 49.4254 & $\mathrm{C}_{29} \mathrm{H}_{50} \mathrm{O}$ \\
\hline 29 & 9,19-Cycloergost-24(28)-en-3-ol, 4,14-dimethyl-, acetate, (3.beta.,4.alpha.,5.alpha.)- & 49.9551 & $\mathrm{C}_{32} \mathrm{H}_{52} \mathrm{O}_{2}$ \\
\hline 30 & 9,19-Cycloergost-24(28)-en-3-ol, 4,14-dimethyl-, acetate, (3.beta.,4.alpha.,5.alpha.)- & 50.3849 & $\mathrm{C}_{32} \mathrm{H}_{52} \mathrm{O}_{2}$ \\
\hline 31 & alpha-Amyrin & 50.6464 & $\mathrm{C}_{30} \mathrm{H}_{50} \mathrm{O}$ \\
\hline
\end{tabular}


recorded every day until the death of the last fly.

\subsection{GC-MS analysis of TCE}

GC-MS instrument (7890B GC/5977B MSD, Agilent Technologies, Santa Clara, CA, USA) connected with an HP-5MS capillary column of $25 \mathrm{~m}$ x $250 \mu \mathrm{m} \times 0.25$ $\mu \mathrm{m}$ was used to measure the phytochemical presence in the TCE. The extract was diluted with ethanol and injected in splitless mode. The condition of oven temperature was $60^{\circ} \mathrm{C}$ holding for $0 \mathrm{~min}$, and increased to $300^{\circ} \mathrm{C}$ at a rate of $5 \mathrm{C} / \mathrm{min}$. Helium (99.999\%) was used as carrier gas and delivered at a flow rate of $1.0 \mathrm{~mL} / \mathrm{min}$. The MS temperature of ion source was $230^{\circ} \mathrm{C}$ with EI type of $70 \mathrm{eV}$ and quadrupole temperature at $150^{\circ} \mathrm{C}$. The analysis of results was performed in scan mode start mass 35 end mass 550. The data was presented as retention time and chemical formula as shown in Table 1.

\subsection{Statistical analysis}

SPSS 20.0 (SPSS Inc., Chicago, USA) was used to analyze all of the data. The means of the groups were compared using a one-way ANOVA. The Kaplan-Meier test was used to determine the difference between the survival curves. The data was presented as a mean with a standard deviation (SD). Differences were considered significant when $P<0.05$.

\section{RESULTS}

\subsection{Effect of TCE on food intake of fruit flies}

To ensure that the life span extension observed in the life span experiment was not due to caloric restriction, food intake was measured. As showed in Figure 1, food intake was lower in the $30 \mathrm{mg} / \mathrm{mL}$ TCE group than in the control group $(P<0.01)$. The control, 5, 10, and 20 $\mathrm{mg} / \mathrm{mL}$ TCE-fed flies showed no significant differences. Therefore, in the subsequent experiments in this study, we used a concentration of 10 and $20 \mathrm{mg} / \mathrm{mL}$.

\subsection{Effect of TCE on the longevity of fruit flies}

The effect of TCE on the life span of fruit flies was demonstrated in Figure 2A. In control, TCE10, and TCE20 groups, the maximum life spans were 76,80 , and 86 days, respectively. The TCE20 group had a 50\% survival time of 58 days (18.37 percent increase) compared to a $50 \%$ survival time of 49 days in the control group. The mean life span in control, TCE10, and TCE20 groups were $47 \pm 3.52,55 \pm 5.51$, and $60 \pm 3.34$ days, respectively. As shown in Figure 2A, supplementation with TCE20 could significantly prolong fruit flies' life span $(P<0.01)$. However, no significant difference was found in TCE10 treatment flies compared with the control group and with the TCE20 group.

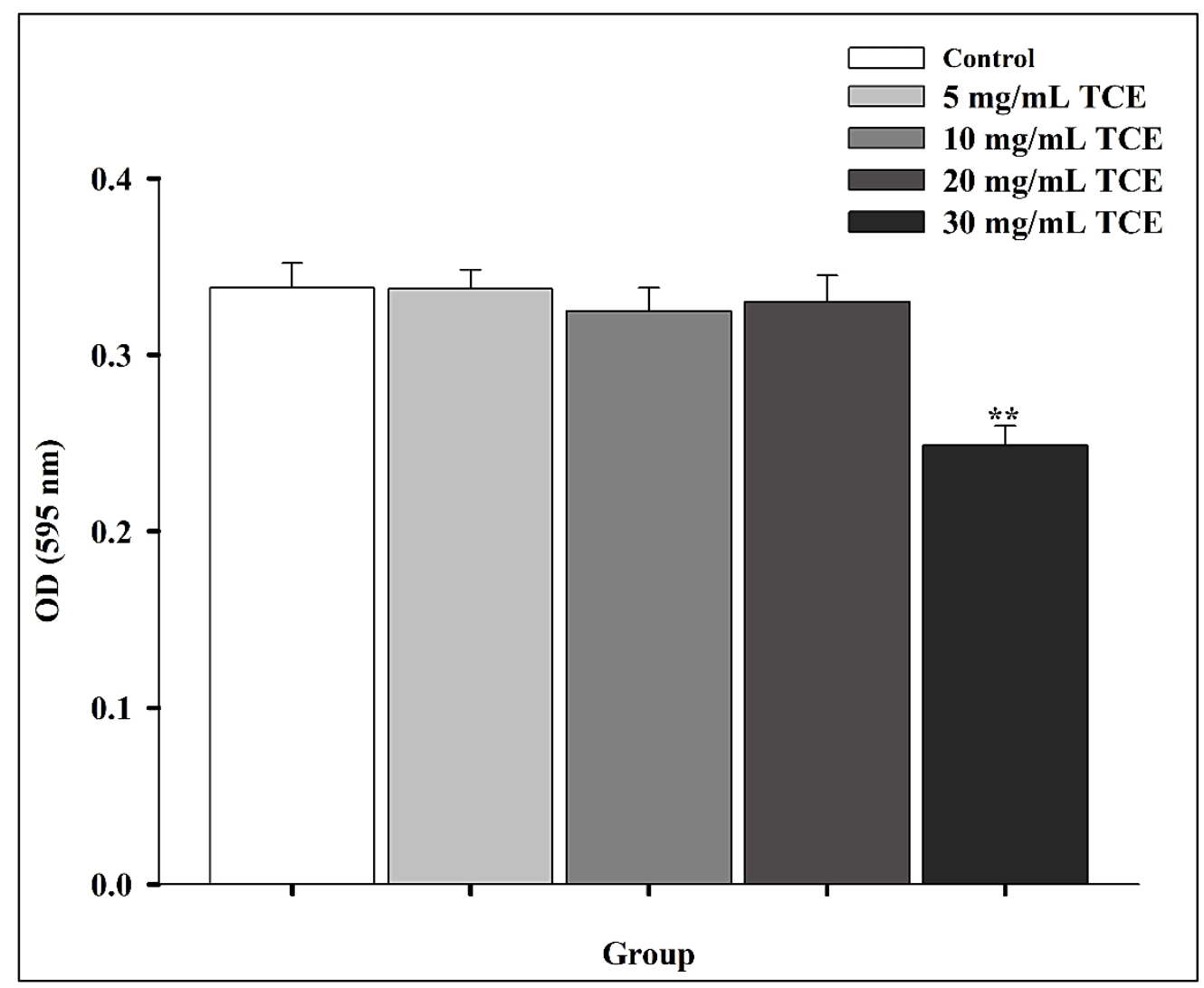

Figure 1. Food intake by gustatory assay of D. melanogaster in the control group and diet containing 5, 10, 20, and $30 \mathrm{mg} / \mathrm{mL}$ TCE groups (n=100 per group). The data is presented as a mean \pm SD. $* *$ indicates a statistically significant difference from the control group at $P<0.01$. 


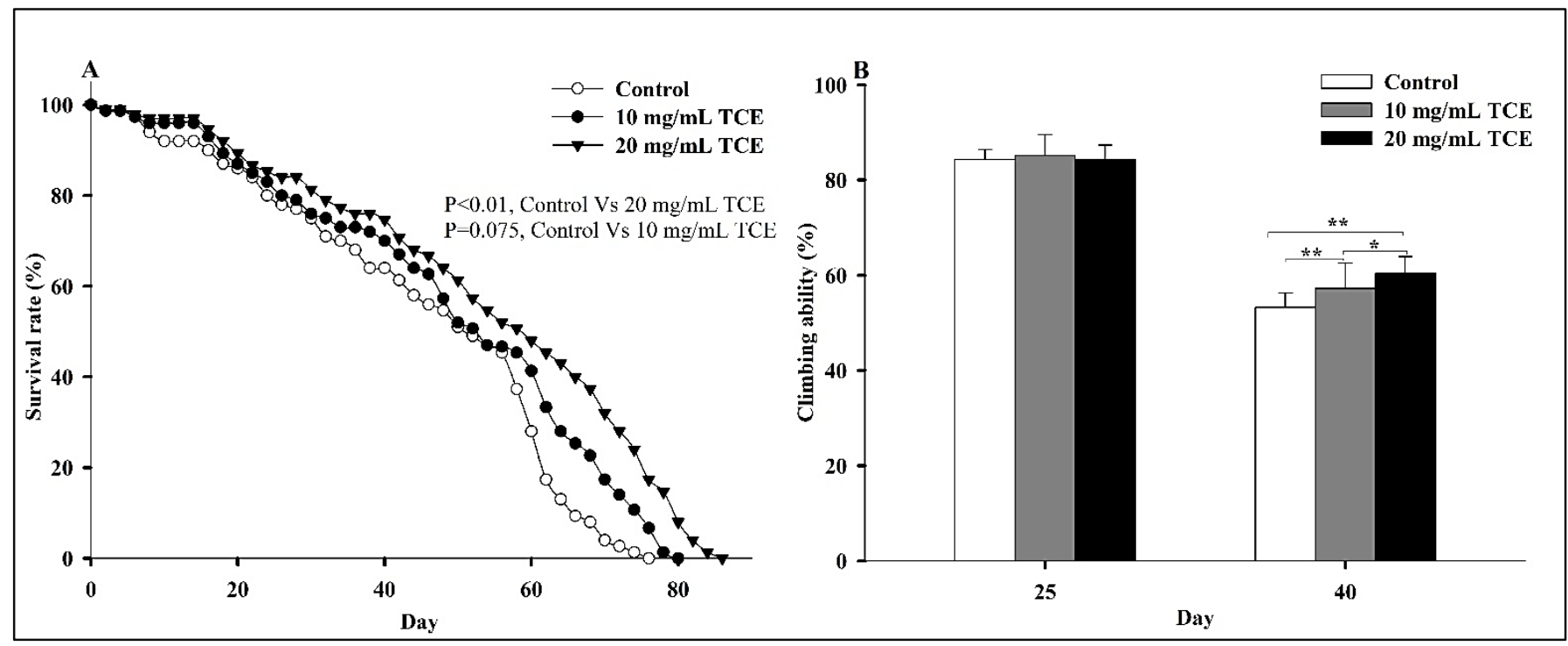

Figure 2. The effect of TCE on the life span extension (A) and climbing ability (B) in Drosophila ( $\mathrm{n}=200$ per group). The data is presented as a mean \pm SD. * and ** indicate statistically significant differences from the control group at $P<0.05$ and $P<0.01$, respectively.

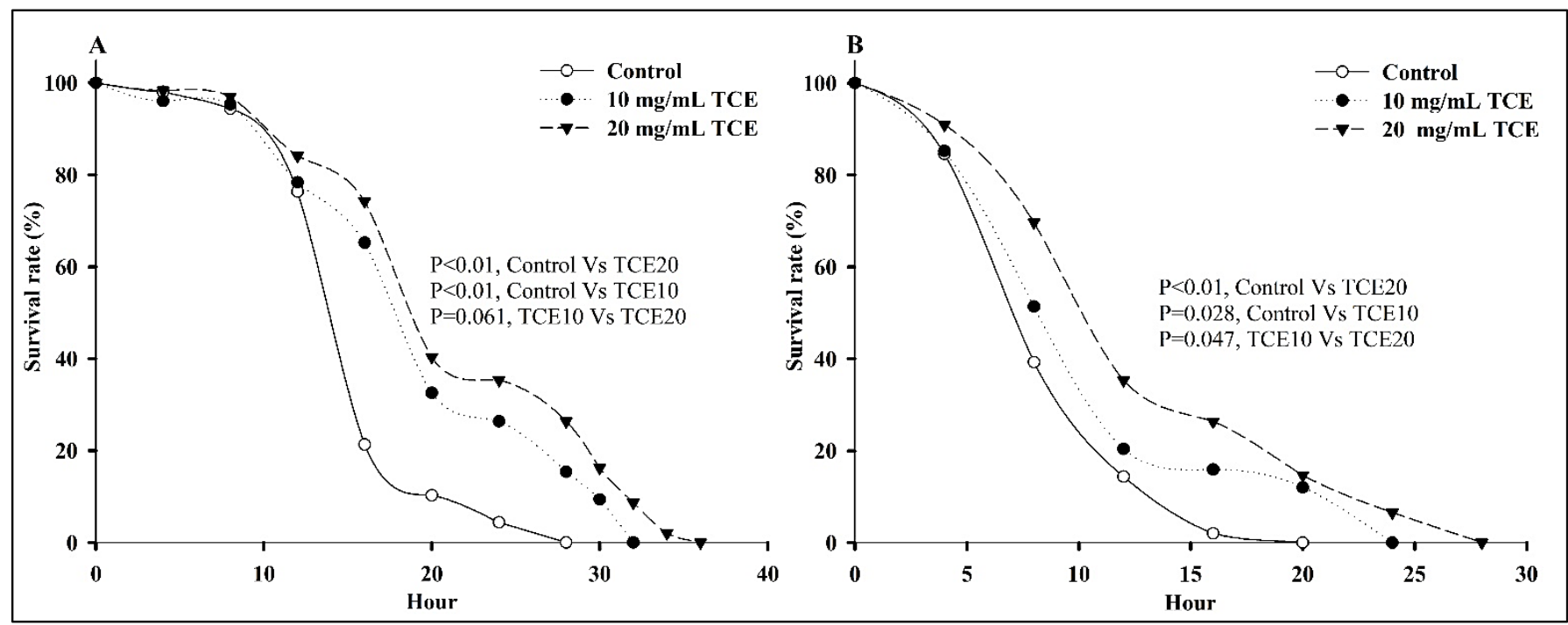

Figure 3. Effect of TCE supplementation on the resistance to paraquat (A) and hydrogen peroxide (B) exposure in Drosophila fed with control diet and diets containing 10 and $20 \mathrm{mg} / \mathrm{mL}$ TCE ( $\mathrm{n}=200$ per group). The Kaplan-Meier and log-rank tests were used to examine the survival test. The statistical significance was considered at $P<0.05$.

The climbing assay was used to evaluate the flies' physical strength. As shown in Figure 2B, there was no significant difference in climbing ability between the tested groups on day 25 . On days 40, TCE supplementation in a mixed diet at concentrations of 10 and $20 \mathrm{mg} /$ $\mathrm{mL}$ could significantly improve the physical performance of fruit flies. There was also a significant difference between the two extract groups. These results indicate that supplementation with TCE can extend Drosophila's life span and increase its physical strength.

\subsection{Effect of TCE on the oxidative stress resistance}

A by-product of paraquat is a superoxide radical, which is a highly reactive oxygen species. Figure $3 \mathrm{~A}$ shows the effect of TCE on the fruit flies' oxidative stress resistance to paraquat-induced free radicals. In control, TCE10, and TCE20 groups, the maximum survival time were 28,32 , and $36 \mathrm{~h}$, respectively. The $50 \%$ survival times were $13.74,18.35$, and 20.66 h, respectively. The KaplanMeier test revealed that supplementing fruit flies with TCE10 and TCE20 significantly enhanced their survival time $(P<0.01)$. However, there was no significant difference between the TCE10 and TCE20 groups.

A similar result was observed in the hydrogen peroxide challenge test. As shown in Figure 3B, TCE10 and TCE20 flies had significantly longer survival times than control flies $(P=0.028$ and $P<0.01$, respectively). A significant difference was also observed between the two extract groups. The maximum survival times in the control, TCE10, and TCE20 groups were 20, 24, and 28 hours, respectively. The 50\% survival times in the control, 


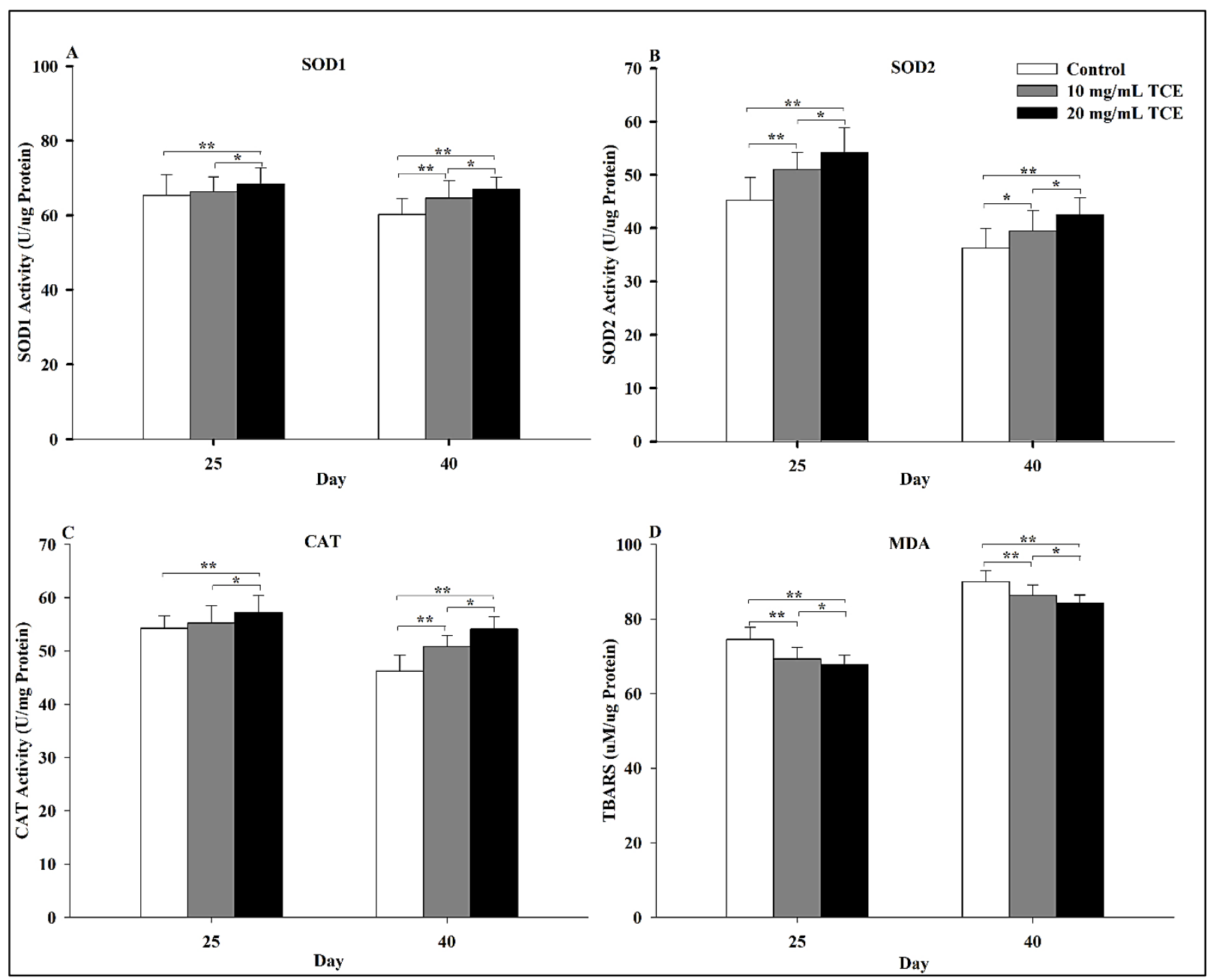

Figure 4. Effect of TCE supplementation on the activities of SOD1 (A), SOD2 (B), and CAT (C) in Drosophila reared on the control diet and diets containing 10 and $20 \mathrm{mg} / \mathrm{mL}$ TCE on the day of 25 (adult flies) and 40 (aged flies) ( $\mathrm{n}=200$ per group). The data is presented as a mean \pm SD. $*$ and $* *$ indicate significant differences compared to the control group at $P<0.05$ and $P<0.01$, respectively.

TCE10, and TCE20 groups were 7.18, 8.05, and $10.22 \mathrm{~h}$, respectively. These findings suggest that supplementing Drosophila with TCE significantly increased its resistance to oxidative stress induced by free radicals.

\subsection{Effect of TCE on the antioxidant enzyme activities}

The effect of TCE on the antioxidant enzyme activities of fruit flies was shown in Figure 4. The results in Figure 4 demonstrated that TCE supplementation could significantly enhance SOD1, SOD2, and CAT activities. A similar result was observed in the SOD1 and CAT activities. As shown in Figure 4A and Figure $4 \mathrm{C}$, on days 25 and 40 , supplementation with $20 \mathrm{mg} / \mathrm{mL}$ TCE significantly enhanced SOD1 and CAT activities $(P<0.01)$, whereas supplementation with $10 \mathrm{mg} / \mathrm{mL}$ TCE significantly increased SOD1 and CAT activities only on day $40(P<0.01)$. The results in Figure 4B demonstrated that supplementation with TCE at concentrations of 10 and $20 \mathrm{mg} / \mathrm{mL}$ resulted in a significant increase in SOD2 activity on days 25 and 40 . Significant differences were found between the TCE10 and TCE20 groups as to the activities of all tested enzymes. In this study, the measurement of the total body lipid peroxidation (LPO) level was performed to verify the antioxidant activities. As shown in Figure 4D, TCE treatment at 10 and $20 \mathrm{mg} /$ $\mathrm{mL}$ for 25 and 40 days significantly reduced LPO levels. The LPO levels were significantly different between the TCE10 and TCE20 groups. These results indicate that supplementing Drosophila with TCE increased the activity of antioxidant enzymes significantly.

\subsection{Effect of TCE on stress resistance}

The enhancement in resistance to heat, cold, acetic acid, and starvation stress in flies was evaluated in this study to verify TCE's life span activities. As shown in Figure 5A-D, supplementation with TCE at a $20 \mathrm{mg} / \mathrm{mL}$ concentration could significantly increase the \% survival rate of treated flies following heat, cold, acetic acid, and starvation stresses when compared to control flies. With $10 \mathrm{mg} / \mathrm{mL}$ TCE treatment, the treate flies were more resistant to cold and acetic acid than the control flies (Figure 5B-C). However, no significant difference was found when compared between two extract concentration groups. These findings suggest that supplementation 


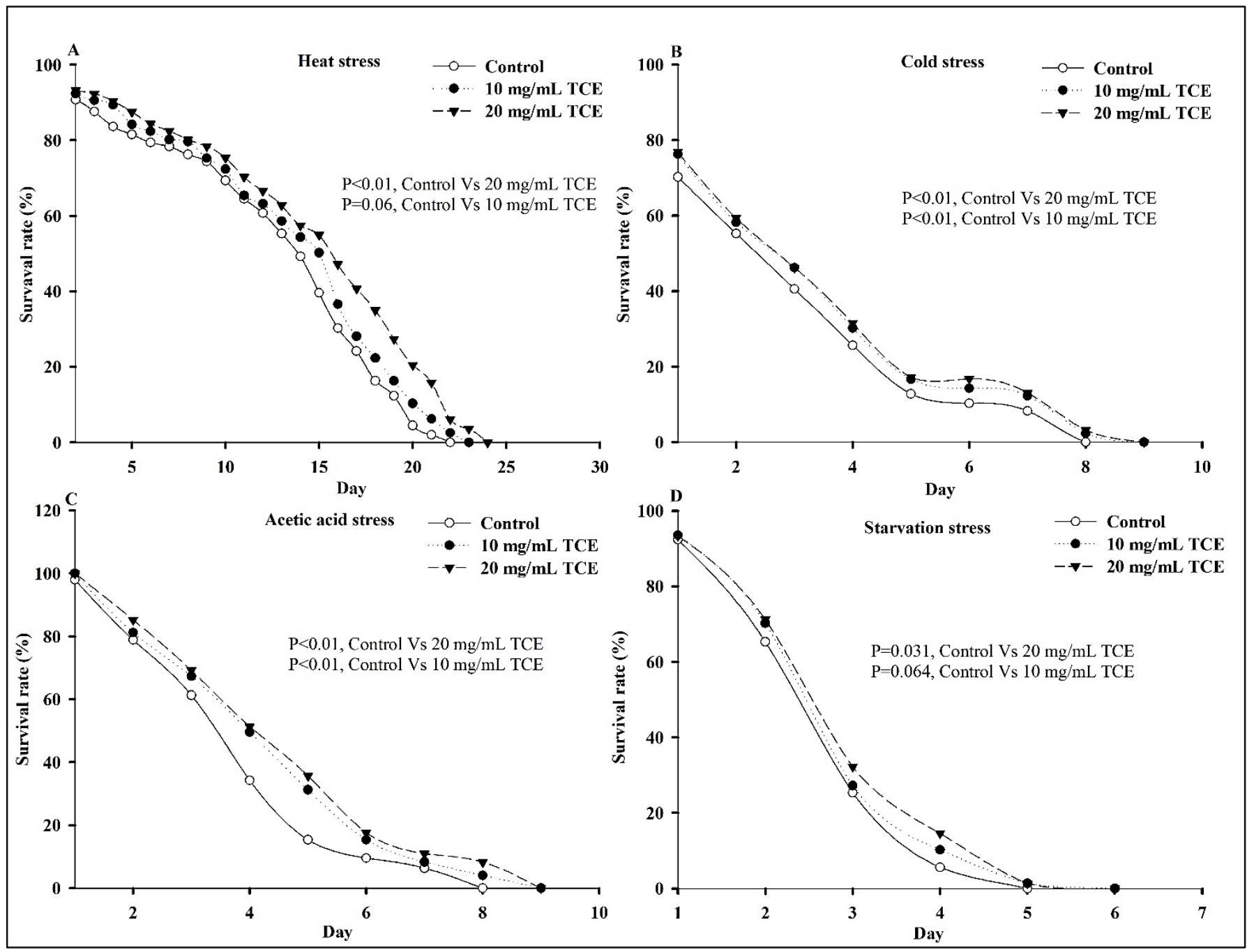

Figure 5. Effect of TCE supplementation on the improvement of the recovery from cold (A) and heat shocks (B), the resistance to acetic acidinduced oxidative stress (C), and starvation stress (D) in TCE-treated Drosophila ( $\mathrm{n}=200$ per group). The survival test was analyzed using Kaplan-Meier and log-rank test. The statistical significance was considered at $P<0.05$.

with TCE can enhance adaptive capacity in Drosophila.

\section{DISCUSSION}

Healthy span has been a recent challenge to reduce the specific diseases and extend the number of years of healthy living. It is postulated that the deceleration of aging will save around seven trillion dollars in 50 years ${ }^{37}$. Nowadays, plant-based supplements play an essential factor in slowing aging. Based on ancient knowledge, many plants have been used as an effective ingredient in longevity remedies. T. crispa is an herbal plant used as a longevity medicine in Thailand. To verify the traditional use, the present study was conducted to investigate the longevity property of an ethanolic extract of this plant using fruit flies as a model. Results clearly demonstrated that TCE showed to increase the life span of fruit flies. Our findings are consistent with a previous study that found that supplementing diets with fine powdered T. cordifolia stems at concentrations of 0.25 , 0.5 , and $0.7 \mathrm{~g} / 100 \mathrm{~mL}$ could increase the life span of
Drosophila in both the parent and F-1 generations ${ }^{38}$. Supplementation of TCE in the diet showed to improve the climbing ability of fruit flies. One of the mechanisms by which TCE extends the life span of fruit flies could be its anti-oxidative property. Among over 300 theories of aging, the Free Radical Theory of Aging is the most typically suggested characteristic of aging to explain the aging mechanism at the cellular level ${ }^{39}$. An imbalance between free radical production and the antioxidant defense system can cause the accumulation of oxidative stress, which significantly influences the progression of aging ${ }^{40}$. Thus, one of the key challenges for the research direction is identifying the most effective agent for longevity promotion to prolong life span and reach healthy aging ${ }^{41-42}$. Our results showed increased resistance to oxidative stress after exposure to hydrogen peroxide and paraquat of TCE-treated flies may explain the cellular mechanism by which TCE exhibits longevity activity of the fruit flies may be related to its antioxidant activity. Our findings agree with the previous studies that reported that the stems of $T$. crispa could exhibit 
antioxidant properties ${ }^{19-20}$. Using GC-MS analysis, we discovered that the ethanolic extract of TCE contains several compounds that have been shown to be antioxidants, including phytol $^{43}$, beta-sitosterol, stigmasterol, campesterol $^{44}$, and alpha-amyrin ${ }^{45}$. Concerning our results, several studies conducted in the Drosophila model also demonstrated that supplementation with dietary antioxidants was associated with the life span extension in fruit flies, such as green tea catechins and broccoli ${ }^{46}$, $\operatorname{cocoa}^{47}$, curcumin $^{48}$, apple polyphenols ${ }^{49}$, lutein ${ }^{50}$, ellagic $\operatorname{acid}^{51}$, and xanthohumol ${ }^{52}$.

The endogenous oxidative defense system also plays a vital role in the life span extension of Drosophila. The previous study found that antioxidant enzyme activity decreases were associated with age ${ }^{53}$. The overexpression of SOD and CAT genes in Drosophila was positively related to the maximal life $\operatorname{span}^{54}$. On the other hand, the deletion of the SOD2 gene in Drosophila severely shortened its life $\operatorname{span}^{55-56}$. The long-lived strain of Drosophila displayed the higher activities of SOD and CAT throughout its life span than the short-lived strain $^{57}$. In this study, supplementation with TCE was shown to activate the antioxidant enzymes' activities, including SOD1, SOD2, and CAT, with decreasing LPO levels of TCE-treated flies. This study suggested that one of the possible mechanisms for the longevity activity of TCE in Drosophila is the stimulation of SOD1, SOD2, and CAT activities.

Senescence can be quantified functionally by evaluating the flies' life span and climbing ability, which both reflect the functional status of muscle and locomotor function ${ }^{58}$. Antioxidant activity may be beneficial in preventing the oxidative stress that contributes to the development of a variety of diseases, including neurological disorders. It has been established that exposure to the free radical paraquat is associated with impaired locomotor function and neurodegenerative disorders such as Parkinson's disease ${ }^{49}$. As a result, one possible mechanism by which TCE supplementation improves motor function is through its antioxidant activity. Our hypothesis is supported by the paraquat challenge test, which demonstrated that supplementing Drosophila with TCE can reduce mortality and improve locomotor activity. However, our study has a weakness in that we did not verify the mechanism at the mRNA level. The previous studies have demonstrated that climbing ability of fruit fly was correlate with $\mathrm{srl}$ expression ${ }^{59-60}$. This gene is an ortholog of mammalian PGCla, which plays a critical role in energy homeostasis regulation and muscle atrophy prevention ${ }^{61}$. Downregulation of $s r l$ expression resulted in a reduction in the lifespan of Drosophila ${ }^{62}$. Thus, future research should be directed toward understanding the mechanisms underlying TCE's context-dependent effect on locomotor function.

Adaptive Homeostasis Theory of Aging is also another key theory to clarify the process of aging. It is widely accepted that the decline of resistance to physiological stresses is associated with aging progress ${ }^{63}$. The decline in adaptive capacity was proved to associate with age in Drosophila model ${ }^{64-66}$. Thus, the enhancement of adaptive response should ultimately prolong the life span. The findings from previous Drosophila research have shown that supplementation with phytochemical compounds could improve adaptive capacity in stressinduced aging, such as rutin ${ }^{35,67}$, ellagic acid ${ }^{51}$, naringe$\operatorname{nin}^{68}$, and xanthohumol ${ }^{52}$. In this study, supplementation with TCE improved the recovery from cold and heat shocks in Drosophila. The resistance to starvation stress and oxidative stress induced by free radicals $\left(\mathrm{H}_{2} \mathrm{O}_{2}\right.$, paraquat, and acetic acid) were also investigated in the TCE-treated flies. Our findings verify the longevity properties of TCE as a protective factor that may help increase resistance ability to physiological stressors. Numerous ageing theories attribute life span to an individual's capacity to withstand extrinsic or intrinsic stresses. As a result, longevity should be positively related to the capacity to cope with stress ${ }^{69}$. The expression of stress proteins occurs during the stress response. Heat shock proteins are intriguing candidates for a mechanism underlying generalized stress. They are expressed in a variety of ways in response to a variety of stresses such as oxidative stress, starvation and thermal stress ${ }^{70-}$ ${ }^{72}$. Overexpression of the heat shock protein transcripts $h s p 22$ and $h s p 23$ has been shown to improve life span and resistance to stress ${ }^{73}$. Nonetheless, it has been demonstrated that decreased Hsp70 expression correlates with life span extension ${ }^{74}$. TCE's ability to improve the stress response may be due to its modulation of heat shock proteins. The butanolic extract of $T$. cordifolia was shown to have neuroprotective properties by inhibiting HSP70 expression in glutamate-induced excitotoxicity in primary cerebellar neuronal cultures ${ }^{75}$. Although the exact mechanism by which TCE improves Drosophila's ability to resist stress-induced mortality was not determined in this study, it established TCE's effect on stress response. Thus, future research should focus on elucidating the mechanisms by which TCE affects the expression of stress response proteins.

In summary, the current study suggests that TCE may have anti-aging properties. Further studies are needed to verify the signaling pathways of TCE regarding life span prolongation. Besides, further studies in the mammal model are also required to confirm TCE's role in longevity property.

\section{CONCLUSIONS}

This study verified the traditional longevity property of $T$. crispa extract in Drosophila. Supplementation with $T$. crispa extract at $20 \mathrm{mg} / \mathrm{mL}$ in a mixed diet significantly increased the mean life span, improved the resistance to free radicals induced oxidative stress, 
improved the locomotor activity, stimulated the activity of antioxidant enzymes, improved the recovery from cold and heat shocks, and increased the resistance to starvation and acetic acid-induced stresses.

\section{ACKNOWLEDGEMENT}

The wild-type Drosophila was provided by Assistant Professor Dr. Monthira Monthatong, Department of Biology, Faculty of Sciences, Khon Kaen University, Thailand. The authors are grateful to Ubon Ratchathani Rajabhat University, Faculty of Thai Traditional and Alternative Medicine, for supplying instruments.

\section{Conflict of interest}

The authors declare that there is no conflict of interests regarding the publication of this manuscript.

\section{Funding}

None to declare.

\section{Ethics approval}

The animal research design was approved by the Ethic Committee of Ubon Ratchathani Rajabhat University, Thailand (Ethical Clearance No. AN63001).

\section{Article info:}

Received July 1, 2021

Received in revised form October 5, 2021

Accepted October 6, 2021

\section{REFERENCES}

1. He S, Sharpless NE. Senescence in Health and Disease. Cell. 2017;169(6):1000-11.

2. Gallo Marin B, Aghagoli G, Lavine K, Yang L, Siff EJ, Chiang SS, et al. Predictors of COVID-19 severity: A literature review. Rev Med Virol. 2021;31(1):1-10.

3. United Nations. The 2019 Revision of World Population Prospects website. [document on the Internet]. New York: The United Nations; 2019. Available from: https://population.un.org/wpp/.

4. Beckman KB, Ames BN. The free radical theory of aging matures. Physiol Rev. 1998;78(2):547-81.

5. Valko M, Leibfritz D, Moncol J, Cronin MT, Mazur M, Telser J. Free radicals and antioxidants in normal physiological functions and human disease. Int J Biochem Cell Biol. 2007;39(1):44-84.

6. Finkel T, Holbrook NJ. Oxidants, oxidative stress and the biology of ageing. Nature. 2000;408(6809):239-47.

7. Pham-Huy LA, He H, Pham-Huy C. Free radicals, antioxidants in disease and health. Int J Biomed Sci. 2008;4(2):89-96.

8. Willis LM, Shukitt-Hale B, Joseph JA. Modulation of cognition and behavior in aged animals: Role for antioxidant- and essential fatty acid-rich plant foods. Am J Clin Nutr. 2009;89(5):1602S-6S.

9. Kim SI, Jung JW, Ahn YJ, Restifo LL, Kwon HW. Drosophila as a model system for studying lifespan and neuroprotective activities of plant-derived compounds. J Asia-Pac Entomol. 2011; 14(4):509-71.

10. Lee SH, Min KJ. Drosophila melanogaster as a model system in the study of pharmacological interventions in aging. Transl Med Aging. 2019;3:98-103.

11. Panchal K, Tiwari AK. Drosophila melanogaster "a potential model organism" for identification of pharmacological proper- ties of plants/plant-derived components. Biomed Pharmacother. 2047;89:1331-45

12. Chattopadhyay D, Thirumurugan K. Longevity promoting efficacies of different plant extracts in lower model organisms. Mech Ageing Dev. 2018;171:47-57.

13. Piper M, Partridge L. Drosophila as a model for ageing. Biochim Biophys Acta Mol Basis Dis. 2018;1864(9 Pt A):2707-17.

14. Bass TM, Weinkove D, Houthoofd K, Gems D, Partridge L. Effects of resveratrol on lifespan in Drosophila melanogaster and Caenorhabditis elegans. Mech Ageing Dev. 2007;128(10): 546-52.

15. Pallauf K, Duckstein N, Rimbach G. A literature review of flavonoids and lifespan in model organisms. Proc Nutr Soc. 2017;76(2):145-62.

16. Pathak AK, Jain DC, Sharma RP. Chemistry and biological activities of the genera. Tinospora. Pharm Biol. 1995;33(4):277-87.

17. Hipol RLB, Cariaga MFNM, Hipol RM. Anti-inflammatory activities of the aqueous extract of the stem of Tinospora crispa (Family Menispermaceae). J Nat Stud. 2012;11:88-95.

18. Kamarazaman IS, Amorn Z, Ali RM. Inhibitory properties of Tinospora crispa extracts on TNF- $\alpha$ induced inflammation on human umbilical vein endothelial cells (HUVECS). Int J Trop Med. 2012;7:24-29.

19. Ibahim M, I'zzah WNW, Narimah A, Asyikin NZ, Shafinas SNS, Froemming G. Anti-proliperative and antioxidant effects of Tinospora crispa (Batawali). Biomed Res India. 2011;22:57-62.

20. Zulkefli HN, Mohama J, Abidin NZ. Antioxidant activity of methanol extract of Tinospora crispa and Tabernaemontana corymbose. Sains Malays. 2013;42:697-706.

21. Sulaiman M, Zakaria Z, Lihan R. Antinociceptive and antiinflamatory activities of Tinospora crispa in various animal models. Int J Top Med. 2008;3:66-9.

22. Sinchaikul S, Chen ST, Sookkheo B. Tumor cell selective antiproliferative effect of the extract from Tinospora crispa (borapet). Bull Health Sci Tech. 2007;7:75-84.

23. Zulkhairi AJr, Abdah MA, Kamal NHM, Nursakinah I, Moklas MA, Hasnah B, et al. Biological properties of Tinospora crispa (Akar Patawali) and its antiproliferative activities on selected human cancer cell lines. Malays J Nutr. 2008;14(2):173-87.

24. Niljan J, Jaihan U, Srichairatanakool S, Uthaipibull C, Somsak V. Antimalarial activity of stem extract of Tinospora crispa against plasmodium berghei infection in mice. J Health Res. 2014;28(3):199-204.

25. Anulukanapakorn K, Pancharoen O, Bansiddhi J. Hypoglycemic effect of Tinospora crispa (Linn.) Mier ex Hook F. \& Thorns (Menispermaceae) in rats. Bull Depart Med Sci. 2012;41:231-43.

26. Lam SH, Ruan CT, Hsieh PH, Su MJ, Lee SS. Hypoglycemic diterpenoids from Tinospora crispa. J Nat Prod. 2012;75(2): 153-9.

27. Praman S, Mulvany MJ, Allenbach Y, Marston A, Hostettmann $\mathrm{K}$, Sirirugsa P, et al. Effects of an $n$-butanol extract from the stem of Tinospora crispa on blood pressure and heart rate in anesthetized rats. J Ethnopharmacol. 2013;133(2):675-86.

28. Praman S, Mulvany MJ, Williams DE, Andersen RJ, Jansakul C. Crude extract and purified components isolated from the stems of Tinospora crispa exhibit positive inotropic effects on the isolated left atrium of rats. J Ethnopharmacol. 2013;149(1):123-32.

29. Abood WN, Fahmi I, Abdulla MA, Ismail S. Immunomodulatory effect of an isolated fraction from Tinospora crispa on intracellular expression of INF-gamma, IL-6 and IL-8. BMC Complement Altern Med. 2014;14:205.

30. Balasubramani SP, Mohan J, Chatterjee A, Patnaik E, Kukkupuni SK, Nongthomba U, et al. Pomegranate juice enhances healthy lifespan in Drosophila melanogaster: An exploratory study. Front Public Health. 2014;2:245.

31. Yoon JS, Gagen KP, Zhu D. Longevity of 68 Species of Drosophila. Ohio J Sci. 1994;90:16-32.

32. Devasagayam TP, Boloor KK, Ramasarma T. Methods for estimating lipid peroxidation: an analysis of merits and demerits. 
Indian J Biochem Biophys. 2003;40(5):300-08.

33. Lee FK, Wong AK, Lee YW, Wan OW, Chan HY, Chung KK. The role of ubiquitin linkages on $\alpha$-synuclein induced-toxicity in a Drosophila model of Parkinson's disease. J Neurochem. 2009; 110(1):208-19.

34. Colpo AC, Lima ME, da Rosa HS, Leal AP, Colares CC, Zago $\mathrm{AC}$, et al. Ilex paraguariensis extracts extend the lifespan of Drosophila melanogaster fed a high-fat diet. Braz J Med Biol Res. 2017;51:e6784.

35. Chattopadhyay D, Chitnis A, Talekar A, Mulay P, Makkar M, James J, et al. Hormetic efficacy of rutin to promote longevity in Drosophila melanogaster. Biogerontology. 2017;183(3):397411.

36. Montooth KL, Siebenthall KT, Clark AG. Membrane lipid physiology and toxin catabolism underlie ethanol and acetic acid tolerance in Drosophila melanogaster. J Exp Biol. 2006;209(Pt 19):3837-50.

37. Goldman DP, Cutler D, Rowe JW, Michaud PC, Sullivan J, Peneva D, et al. Substantial health and economic returns from delayed aging may warrant a new focus for medical research. Health Aff (Millwood). 2013;32(10):1698-705.

38. Pathak P, Vyas M, Vyas H, Naria M. Rasayana effect of Guduchi Churna on the life span of Drosophila melanogaster. Ayu. 2016; 37(1):67-70.

39. López-Otín C, Galluzzi L, Freije JM, Madeo F, Kroemer G. Metabolic control of longevity. Cell. 2016;166(4):802-21.

40. Harman D. Aging: a theory based on free radical and radiation chemistry. J Gerontol. 1956;11(3):298-300.

41. Dhanjal DS, Bhardwaj S, Sharma R, Bhardwaj K, Kumar D, Chopra $\mathrm{C}$, et al. Plant fortification of the diet for anti-ageing effects: a review. Nutrients. 2020;12:3008.

42. Peng C, Wang X, Chen J, Jiao R, Wang L, Li YM, et al. Biology of ageing and role of dietary antioxidants. Biomed Res Int. 2014; 2014:831841.

43. Santos CC, Salvadori MS, Mota VG, Costa LM, de Almeida AA, de Oliveira GA, et al. Antinociceptive and antioxidant activities of phytol in vivo and in vitro models. Neurosci J. 2013;2013: 949452.

44. Yoshida Y, Niki E. Antioxidant effects of phytosterol and its components. J Nutr Sci Vitaminol (Tokyo). 2003;49(4):277-80.

45. Karen Cardoso B, Line Marko de Oliveira H, Zonta Melo U, Mariano Fernandez CM, Franco de Araújo Almeida Campo C, Gonçalves JE, et al. Antioxidant activity of $\alpha$ and $\beta$-amyrin isolated from Myrcianthes pungens leaves. Nat Prod Res. 2020;34 (12):1777-81.

46. Li YM, Chan HYE, Yao XQ, Huang Y, Chen ZY. Green tea catechins and broccoli reduce fat-induced mortality in Drosophila melanogaster. J Nutr Biochem. 2008;19(6):376-83.

47. Bahadorani S, Hilliker AJ. Cocoa confers lifespan extension in Drosophila melanogaster. Nutr Res. 2008;28(6):377-82.

48. Lee KS, Lee BS, Semnani S, Avanesian A, Um CY, Jeon HJ, et al. Curcumin extends life span, improves health span, and modulates the expression of age-associated aging genes in Drosophila melanogaster. Rejuvenation Res. 2010;13(5):561-70.

49. Peng C, Chan HYE, Huang Y, Yu H, Chen ZY. Apple polyphenols extend the mean lifespan of Drosophila melanogaster. J Agric Food Chem. 2011;59(5):2097-106.

50. Zhang Z, Han S, Wang H, Wang T. Lutein extends the lifespan of Drosophila melanogaster. Arch Gerontol Geriatr. 2014;58(1): 153-9.

51. Kharat P, Sarkar P, Mouliganesh S, Tiwary V, Priya V, Sree NY, et al. Ellagic acid prolongs the lifespan of Drosophila melanogaster. Geroscience. 2020;42(1):271-85.

52. Wongchum N, Dechakhamphu A. Xanthohumol prolongs lifespan and decreases stress-induced mortality in Drosophila melanogaster. Comp Biochem Physiol C Toxicol. Pharmacol. 2021;244:108994.

53. Sohal RS, Arnold L, Orr WC. Effect of age on superoxide dismutase, catalase, glutathione reductase, inorganic peroxides,
TBA-reactive material, GSH/GSSG, NADPH/NADP+ and NADH/ NAD+ in Drosophila melanogaster. Mech Ageing Dev. 1990;56 (3):223-35

54. Orr WC, Sohal R. Extension of life-span by overexpression of superoxide dismutase and catalase in Drosophila melanogaster. Science. 1994;263(5150):1128-30.

55. Duttaroy A, Paul A, Kundu M, Belton A. A Sod2 null mutation confers severely reduced adult life span in Drosophila. Genetics. 2003;165(4):2295-9.

56. Phillips JP, Campbell SD, Michaud D, Charbonneau M, Hilliker AJ. Null mutation of copper/zinc superoxide dismutase in Drosophila confers hypersensitivity to paraquat and reduced longevity. Proc Natl Acad Sci USA. 1989;86(8):2761-5.

57. Arking R, Burde V, Graves K, Hari R, Feldman E, Zeevi A, et al. Forward and reverse selection for longevity in Drosophila is characterized by alteration of antioxidant gene expression and oxidative damage patterns. Exp Gerontol. 2000;35(2):167-85

58. Iliadi KG, Knight D, Boulianne GL. Healthy aging-insights from Drosophila. Front Physiol. 2012;3:106.

59. Piegholdt S, Rimbach G, Wagner AE. The phytoestrogen prunetin affects body composition and improves fitness and lifespan in male Drosophila melanogaster. FASEB J. 2016;30:948-58.

60. Wagner AE, Piegholdt S, Rabe D, Baenas N, Schloesser A, Eggersdorfer M, et al. Epigallocatechin gallate affects glucose metabolism and increases fitness and lifespan in Drosophila melanogaster. Oncotarget. 2015;6(31):30568-78.

61. Lopez-Otin C, Galluzzi L, Freije JM, Madeo F, Kroemer G. Metabolic control of longevity. Cell. 2016;166:802-21.

62. Mukherjee S, Basar MA, Davis C, Duttaroy A. Emerging functional similarities and divergences between Drosophila Spargel/ dPGC-1 and mammalian PGC-1 protein. Front Genet. 2014;5: 216.

63. Pomatto LCD, Davies KJA. Adaptive homeostasis and the free radical theory of ageing. Free Radic Biol Med. 2018;124:420-30.

64. Pomatto LCD, Wong S, Carney C, Shen B, Tower J, Davies KJA. The age-and sex-specific decline of the 20 s proteasome and the $\mathrm{Nrf} 2 / \mathrm{CncC}$ signal transduction pathway in adaption and resistance to oxidative stress in Drosophila melanogaster. Aging (Albany NY). 2017;9(4):1153-85.

65. Pomatto LCD, Carney C, Shen B, Wong S, Halaszynski K, Salomon MP, et al. The mitochondrial lon protease is required for age-specific and sex-specific adaptation to oxidative stress. Curr Biol. 2017;27(1):1-15.

66. Pomatto LCD, Davies KJA. The role of declining adaptive homeostasis in ageing. J Physiol. 2017;595(24):7275-309.

67. Chattopadhyay D, Thirumurugan K. Longevity-promoting efficacies of rutin in high fat diet fed Drosophila melanogaster. Biogerontology. 2020;21(5):653-68.

68. Chattopadhyay D, Sen S, Chatterjee R, Roy D, James J, Thirumurugan K. Context- and dose-dependent modulatory effects of naringenin on survival and development of Drosophila melanogaster. Biogerontology. 2016;17(2):383-93.

69. Kirkwood TBL, Austad SN. Why do we age?. Nature. 2000;408: 233-8.

70. Landis GN, Abdueva D, Skvortsov D, Yang J, Rabin BE, Carrick J, et al. Similar gene expression patterns characterize aging and oxidative stress in Drosophila melanogaster. Proc Natl Acad Sci USA. 2004;101:7663-8.

71. Sørensen JG, Kristensen TN, Loeschcke V. The evolutionary and ecological role of heat shock proteins. Ecol Lett. 2003;6:1025-37.

72. Zou S, Meadows S, Sharp L, Jan LY, Jan YN. Genomewide study of aging and oxidative stress response in Drosophila melanogaster. Proc Natl Acad Sci USA. 2000;97:13726-31.

73. Kurapati R, Passananti HB, Rose MR, Tower J. Increased hsp22 RNA levels in Drosophila lines genetically selected for increased longevity. J Gerontol A Biol Sci Med Sci. 2000;55A: B552-9.

74. Norry FM, Loeschcke V. Heat-induced expression of a molecular chaperone decreases by selecting for long-lived individuals. 
Exp Gerontol. 2003;38:673-81.

75. Sharma A, Kaur G. Tinospora cordifolia as a potential neuroregenerative candidate against glutamate induced excitotoxicity: an in vitro perspective. BMC Complement Altern Med. 2018; 18:268. 